\title{
A RESSIGNIFICAÇÃo da CULTURA A PARTIR DA REVOLUÇão CIENTÍFICA: UM ESTUdO A PARTIR DA FENOMENOLOGIA DE MICHEL HENRY
}

\author{
[THE RESIGNIFICATION OF CULTURE FROM THE SCIENTIFIC REVOLUTION: A STUDY BASED ON \\ MiCHEL HENRY'S PHENOMENOLOGY]
}

\author{
Janessa Pagnussat * \\ Universidade Federal de Santa Maria, Brasil \\ Silvestre Grzibowski ** \\ Universidade Federal de Santa Maria, Brasil
}

\begin{abstract}
Resumo: O presente artigo tem como objetivo descrever a cultura como manifestação da vida originária, a barbárie como resultado da chegada da revolução científica moderna e a ressignificação da vida e da cultura a partir dessa objetividade do ser. Partimos da teoria de Michel Henry de que a vida se manifesta de forma originária e absoluta, em sua sensibilidade, constituindo a cultura e a arte como manifestações concretas da vida em suas diferentes formas elementares. Porém, com a chegada da ciência, a subjetividade foi sendo objetivada levando ao esquecimento da vida e a decadência cultural, o que originou a barbárie. Na obra $A$ Barbárie, Henry descreve essa mudança radical ocorrida com a revolução científica em que a cultura e a vida foram ressignificadas. Assim, pretendemos descrever essas novas concepções a partir de uma proposta fenomenológica e a possibilidade de um retorno a vida e a sensibilidade originária que foram esquecidas pela sua objetivação.
\end{abstract}

Palavras-chave: Michel Henry; Vida; Cultura; Ciência; Barbárie
ABSTRACT: This article aims to describe culture as a manifestation of original life, barbarism as a result of the arrival of the modern scientific revolution and the resignification of life and culture based on this objectivity of be. We start from Michel Henry's theory that life manifests itself in an original and absolute, in its sensitivity, constituting culture and art as concrete manifestations of life in its different elementary forms. However, with the arrival of science, subjectivity became objectified leading to forgetfulness of life and cultural decay, which originated barbarism. In A Barbárie, Henry describes this radical change that occurred with the scientific revolution in which culture and life were reframed. Thus, we intend to describe these new conceptions from a phenomenological proposal and the possibility of a return to life and the original sensitivity that were forgotten by its objectification.

KeYwords: Michel Henry. Life. Culture. Science. Barbarism.

M ichel Henry criou a fenomenologia da Vida, ou a fenomenologia material. O objetivo desta é fazer uma revisão teórica da tradição fenomenológica, pois, segundo ele, essa não trabalhou a vida originária. Além de ser um crítico da tradição fenomenológica, questionou à ciência porque essa excluiu a sensibilidade, a vida subjetiva. Esse modo de pensar tornou-se único, totalitário e excludente e assim conduziu a humanidade a barbárie. No entanto, Henry mostra que a vida subjetiva que é vivenciada na cultura antecede a barbárie. Encontramos duas teorias com os seus

* Doutoranda do Programa de Pós-graduação em Filosofia da Universidade Federal de Santa Maria, UFSM. E-mail: janessapagnussat@hotmail.com. ** Doutor em Filosofia. Professor Associado I do programa de Graduação e Pós-graduação em Filosofia da Universidade Federal de Santa Maria,UFSM. E-mail: silboski@yahoo.com.br. 
argumentos. A teoria henryana evidencia que existem caminhos para decifrar não só os males que a barbárie tem provocado na humanidade, mas aponta possibilidades para sair dela. De certo modo, a sua teoria segue sendo uma alternativa para os conflitos atuais, afinal, esperamos e desejamos muito sair da barbárie. E um dos argumentos é de voltarmos novamente para a vida subjetiva, originária. A tese que queremos sustentar neste estudo é que a barbárie é o resultado do modo de pensar da humanidade e a cultura antecede a barbárie.

Inicialmente faremos uma exposição a partir da obra $A$ Barbárie, a fim de descrever algumas concepções acerca da cultura afetada pela sensibilidade que é a Vida. Assim como a vida se manifesta em si mesma, a cultura é afetada pelo ver sensível da vida e se constitui no mundo da vida. A arte como uma forma de cultura é a manifestação concreta da vida em suas diferentes formas elementares. Porém, a partir de Galileu, houve um grande avanço científico no mundo degradando a cultura enquanto manifestação do ser. O mundo da vida foi sendo substituído pela técnica e ressignificando-a. Nesse sentido, a barbárie, enquanto crítica ao esquecimento da vida, nos leva a uma decadência cultural, já que a cultura advém da manifestação originária. Portanto, a cultura, a arte e a vida foram ressignificadas a partir do avanço científico e da barbárie, adotando novas concepções.

\section{A CUltura COMO MANifestaÇão da Vida}

Na obra A Barbárie, Henry descreve a concepção de cultura por meio da manifestação da vida ${ }^{1}$ originária do ser e seu movimento de materializar esse impulso fenomenológico correlato ao saber da Vida. A cultura não se baseia em uma decisão concreta baseada nas experiências já vivenciadas pelo ser, mas se baseia na efetivação fenomenológica experimentada no ser e efetivada em sua originalidade, manifestada em si mesma. Ela é a liberação da energia em sua efetivação fenomenológica e seus modos concretos são resultantes das formas de manifestação dessa cultura. Assim, "se a vida é esse movimento contínuo de autotransformação e de autorrealização, ela é a própria cultura" ${ }^{2}$. A Vida enquanto ser fenomenológico originário e absoluto se manifesta de forma imanente em sua corporeidade e esse movimento próprio do ser também corresponde a uma imanência absoluta.

Assim, se considerarmos a vida uma manifestação subjetiva que se experimenta em sua sensibilidade por meio de pensamentos, emoções, desejos e sentimentos, ela é a fonte para a constituição da cultura enquanto conjunto de respostas patéticas no sentirse, como doação primordial no mundo ${ }^{3}$. Essa sensibilidade do sentir-se a si mesmo intensamente se manifesta na arte por meio de ações adequadas que levam a ética. Por ser a arte resultante da cultura da sensibilidade, esse fundo sagrado e misterioso é designado pela religião. Nesse sentido, a arte, a ética e a religião são necessidades superiores da cultura. Assim, a cultura não se restringe a "simples aplicação de poderes definidos de uma vez por todas, mas justamente seu "desenvolvimento", pois "na medida em que a cultura é cultura da vida e repousa sobre o saber próprio desta última, ela é essencialmente prática. Consiste no autodesenvolvimento das potencialidades subjetivas que compõem esta vida"4. Portanto, a cultura é esse modo de manifestação enquanto autoafecção da vida em si mesma que se manifesta por suas formas e modalidades concretas do saber imediato, assumindo diferentes formas elementares.

Levando em consideração a teoria henriana, Kühn (1944, p.114) afirma que a noção de cultura é a auto-revelação da vida em si mesma e que se manifesta a todo momento de modo transcendental do pathos ${ }^{5}$. Nesse sentido, as emoções, as sensações 
e as impressões sobre uma obra cultural são originadas da vida como um prolongamento do desejo de expressar o próprio sentir, aquele que afeta a si mesmo de forma patética. A vida possui um desejo incessante de se experienciar constantemente e sua sensibilidade ao afetar uma obra de arte se prova na sensação de conhecer totalmente a si mesma.

Para tanto, a cultura designa a primeira manifestação da vida originária, remetendo a sensibilidade da vida e como resultado da subjetividade que se manifesta no mundo. Nesse sentido, "a cultura está ligada ad origine ao que somos, pois ela é a manifestação primeira da vida" (PALOMAR TORRALBO, 2018, p.152, tradução nossa). Assim, Henry destaca a sensibilidade que está no mundo da vida para analisar a arte como cultura, ou seja, a arte pode ser considerada uma forma de saber da cultura desde que seja sensível a vida. Esse conceito de arte é similar ao conceito de cultura, já que "a arte tem as mesmas funções da cultura: o acréscimo de si da vida" (MARTINS; SALDANHA, 2014, p.58). Somente o ser sensível pode ser despertado no mundo da vida diante da arte e construir a cultura.

Pela sensibilidade da vida, uma obra de arte é afetada de modo transcendental. A vida originária em sua sensibilidade afeta a arte e, assim, nossa vida é avaliada pelo critério da arte designando sua origem, afetando nosso corpo para as atividades que a emolduram, como as mãos para a pintura e os olhos que analisam. Nesse sentido, ela "é o modo como somos tocados pela vida" (MARTINS; SALDANHA, 2014, p.58). Portanto, as coisas são sensíveis a posteriori, pois "a sensibilidade funciona como a condição transcendental deste mundo [da vida] e de seu surgimento" ". A essência sensível se autoafecta em sua transcendência, de modo que a própria visão é um ver sensível. Enquanto autoafecção, a relação do ser com o objeto só pode ser considerada se houver uma experiência interior.

A arte é cultura quando ocorre essa experiência interior em que o ser é afetado pela própria sensibilidade. Uma obra de arte se manifesta na própria subjetividade, onde se formam a sensibilidade e cada elemento objetivo da composição. Portanto, designamos "a arte, com efeito, é uma atividade da sensibilidade, a realização de seus poderes, ao passo que, com a eliminação das qualidades sensíveis da natureza, a ciência moderna define seu campo próprio e se define a si mesma por exclusão dessa mesma sensibilidade" ". A função da cultura e da arte é a de colocar em prática os dons e as capacidades que estão na essência do ser, mas, o ver sensível foi sendo excluído pela ciência moderna e distanciando a arte da vida originária. Portanto, não possuindo relação com a vida e com a arte, consequentemente, a ciência moderna não constrói a cultura.

Henry (2012, p.44) enfatiza a aniquilação da cultura gerada pelo grande desenvolvimento, causado pelo avanço tecnológico e que afeta a cultura moderna. Essa idealização tem origem galileana quando começou toda a atividade científica gerando uma contradição com a vida em si mesma. Mas é na própria vida enquanto subjetividade que se desvelam todos os sentimentos do ser em meio a ciência, pois pela redução galileana, o ser originou a ciência mas esqueceu de si mesmo e da própria manifestação da vida. De modo que a vida subjetiva foi esquecida pela ciência. Embora, Husserl resgatou e trouxe a questão da subjetividade para discussão filosófica, mas segundo Henry permaneceu na consciência. "Na atitude natural eu percebo a casa e estou desatento a minha percepção da casa. Sempre tenho consciência do mundo e jamais consciência de minha consciência do mundo"8. E a fenomenologia fará a passagem da atitude natural para a transcendental, onde a consciência refletirá sobre si mesma. No entanto, Henry mostra a importância da fenomenologia por ter trabalhado a subjetividade, porém, será uma subjetividade da consciência. O projeto fenomenológico 
tem como proposição de mostrar a fenomenologia da vida subjetiva. Portanto, a ciência galileana afastou tudo o que é subjetivo e também a própria subjetividade. Nesse sentido, descreveremos a seguir a barbárie como resultado desse avanço científíco e o abandono do saber subjetivo originário.

\section{A BARBÁRIE: ESQUECIMENTO DA VIDA E DECADÊNCIA CULTURAL}

Henry (2012) apresenta uma nova concepção de cultura a partir do avanço significativo da ciência. $\mathrm{O}$ esquecimento da vida se dá a partir da importância que o mundo externo passou a adquirir diante do desenvolvimento tecnológico e científico, resultando na barbárie. Essa ocorre pelos desentendimentos originados pelo esquecimento da vida originária do ser e que levam à desordem cultural, política, moral e religiosa.

A modernidade científica e industrial vem se desenvolvendo e todo o esforço nessa direção está levando para uma dissociação entre ciência e cultura. O sujeito voltase para o capitalismo, o consumismo, o imediatismo e isso acaba degradando a cultura, aquela que só adquire significado a partir da manifestação do mundo da vida. Henry afirma que o conhecimento moderno se volta para a objetividade, divergente do saber da vida que se manifesta na subjetividade como essência pura. Nesse sentido, a ciência se distanciou dessa subjetividade e deu enfoque para a objetividade, gerando uma ausência de afetividade no mundo e distante de um viés cultural.

Henry (2012, p.97) descreve que o grande problema está no próprio fundamento da ciência que leva a barbárie, através da exclusão da subjetividade absoluta, da essência pura do ser e sua sensibilidade. Nesse sentido, a cultura adquire novo significado que se confunde com a ciência. Henry aborda a barbárie como a doença da vida quando ocorre a regressão dos modos da realização da vida. O desenvolvimento científico contamina as modalidades concretas de realização da cultura, por isso afeta a essência do ser de onde procede toda a cultura. Como doença da vida, a barbárie corresponde à técnica, "uma nova barbárie de nosso tempo, em lugar da cultura" . Ela é resultante da falta de cultura e da influência do pensamento materialista, objetivo e científico. Além disso, "a barbárie, na destruição da cultura, é a destruição da vida, de tal maneira que, se a cultura fosse totalmente destruída, não saberíamos que aspecto teria a vida como vida humana" (PALOMAR TORRALBO, 2018, p.156, tradução nossa). A barbárie leva a um viés cultural que se difere da vida devido ao hiperdesenvolvimento da ciência, acompanhado da regressão do saber da vida e de todos os domínios correspondentes.

Essa mudança radical foi o ponto chave da revolução científica que resultou no desenvolvimento da humanidade moderna e que a vida deixou de ser ela mesma enquanto autoafecção. Nesse sentido, a ciência dita tão absoluta na modernidade exclui as outras formas de saber no mundo. Por exemplo, a medicina considerada tão avançada enquanto técnica trata de doenças, mas não de doentes. Atualmente, nos encontramos cada vez mais doentes, acometidos por doenças da vida, influenciadas pela destruição da cultura e que leva a barbárie, mas que essa ciência não consegue tratar os doentes, porque esses estão acometidos por doenças do mundo da vida. Nesse sentido, o saber do homem se difere da cultura e o capitalismo com suas tecnologias deixa de lado as Ciências Humanas que são a fonte do conhecimento da vida. O saber do homem moderno está gerando a barbárie, não como crise da cultura, mas como a destruição desta. Portanto, a vida que é cultura se difere daquela vida em que a ciência possui conhecimento, pois " a cultura não tem originalmente e em si nada a ver com a ciência 
e dela não resulta de modo algum" 10 .

A ciência enquanto ingenium - exercício como modo concreto das possibilidades do ver teórico - afasta a sensibilidade como forma de conceituar a cultura. Por meio da ciência, "a sensibilidade [...] é afastada porque a verdade não reside nelas [nas qualidades sensíveis] nem na subjetividade que constitui sua essência, porque a verdade é uma verdade universal e, como tal, objetiva" 11 . A cultura científica nega a própria vida, consequentemente, se distanciando também da cultura sensível originada dessa vida e se identificando com a objetividade do mundo. Então, a modernidade é acometida pela falta de sensibilidade que se origina do mundo-da-vida e a arte afetada pela manifestação da vida é eliminada.

Nesse sentido, a Estética adquire a designação de ciência da arte como modo de investigação científica pela exclusão da sensibilidade do mundo da vida. Uma obra de arte manifestada, "antes, em sua conexão original com a essência da vida e com o seu efeito de princípio"12, passa a se distanciar da vida, aquela que produz a cultura e seu crescimento, manifestação pura. Nesse sentido, percebemos que a ciência se diverge da vida, mesmo aquela que faz abstração dos objetos sensíveis da natureza por se distanciar dessa manifestação.

A barbárie é a energia subjetiva não utilizada que está na fenomenalidade do crescimento de cada ser. Pelo sofrimento, há uma parada e regressão dessa energia no ser e enquanto autonegação corresponde a barbárie. Tomemos como exemplo, ao considerarmos uma pessoa que trabalha oito horas diárias em uma fábrica ou escritório ou farmácia, "isto, todavia, não é o trabalho, mas seu resultado objetivo, isto, segundo a genial intuição de Marx, não confere um valor, mas recebe um valor, e o recebe do trabalho vivo"13. Portanto, não é o trabalho que resulta na produção do capital, mas o regime capitalista que impõe regras e leis para o indivíduo e o trabalho na sociedade, enquanto um sistema.

Utilizando outro exemplo do próprio Henry, a obra $O$ amor de olhos fechados retrata a destruição da cidade de Aliahova, até então referência cultural, em que a vida originária dos personagens é deixada de lado pela destruição da cultura, disputas políticas, racismo e violência. Toda essa situação pela destruição designa a própria barbárie (HENRY, 2015, p.75). A cidade que antes era afetada pela sensibilidade originária da vida das pessoas que por ali passavam, foi sendo destruída por um caos revolucionário, resultante do consumismo, cientificismo, capitalismo e violência.

Henry evidencia o conhecimento do si mesmo, ao retratar como a solidão faz refletir acerca de determinadas coisas e obter algumas percepções do mundo externo que por vezes passam despercebidas. Na seguinte passagem, isso torna-se mais evidente: "Quantas vezes, ouvi aqui o rumor distante do mar, assisti ao lento recuo da luz, admirei a crista dos arbustos iluminados pelos últimos raios. Como tudo na solidão fica belo! " (HENRY, 2015, p. 132). Porém, pelo avanço científico, a obra se evidencia ao narrar a degradação cultural e a degeneração do saber originário da vida.

Henry descreve que o avanço do conhecimento coloca cada vez mais em dúvida a ciência e são necessárias novas formas para afirmá-la, já que podem ocorrer novas descobertas acerca do homem, do mundo e de toda a existência. Então, ele afirma que "é por isso que quanto mais os conhecimentos progridem, mais o mundo é jogado na incerteza" (HENRY, 2015, p. 165). A decadência da cidade se torna evidente à medida que a cultura que revela a vida dos personagens vai sendo aniquilada também, e por fim, culmina no incêndio de Aliahova. Para tanto, o racismo e o machismo são destacados em meio ao viés político e destrutivo que ocorre na cidade de Aliahova onde as mulheres ainda precisam esconder seus rostos. Uma cidade com um aspecto cultural ideal que se destrói pela ausência da vida e isso afeta também as universidades. 
O verdadeiro ensino que a universidade deve transmitir é a cultura, enquanto "autorrealização da vida sob a forma de seu autocrescimento, e isso no que concerne ao conjunto de possibilidades"14. Porém, o que a universidade apresenta são novos modos de ensinar a partir da técnica, do capitalismo e do mundo acultural acometido pela ausência de vida sensível e originária. A cultura se reestrutura pela técnica, por escombros de museus, monumentos e documentários históricos. A mídia pertence ao mundo da técnica, mas, enquanto cultura na ciência moderna, ela é significativa para o crescimento do ser no mundo da vida? A existência midiática procura transmitir a cultura que se arrasta e Henry a crítica por ocupar o lugar da arte e da cultura e designar algo vazio, irreal e que leva a destruição das universidades.

A universidade seguiu o pressuposto galileano e acultural, deixando de lado a fenomenologia da vida. A filosofia enquanto estudo da subjetividade foi substituída pela ciência galileana retirando seu próprio objeto de estudo, ou seja, o ser e sua essência. Nesse sentido, como consequência, temos uma sociedade privada de cultura e acometida pela barbárie. Henry finaliza a obra $A$ Barbárie deixando uma reflexão muito importante: "Pode o mundo ainda ser salvo por alguns?". Essa reflexão é bem pertinente para o momento atual que nos deparamos, pois talvez estamos no auge da barbárie.

\section{A RESSignificaÇÃo da VIDA E dA CULTURA A PARTIR dA CIÊNCIA}

A partir da barbárie, Henry propõe a fenomenologia como uma proposta para o ressurgimento da significação da vida, já que há um esvaziamento da Vida pela destruição do sentido cultural no mundo. Através da grande mudança que vêm afetando o mundo da ciência pela revolução científica, ele evidencia que o saber não se baseia mais na vida, mas no conhecimento objetivo pela "abstração dos sentidos, ao mesmo tempo que faz abstração da existência de qualidades sensíveis no mundo que ele conhece"15. A ciência passa a construir todas as teorias de funcionamento do mundo e fundamentar as leis de ação do homem.

O ser humano para Henry é um ser que sofre e neste sofrimento se revela, manifesta a sua vida originária. No entanto, o pensamento científico tendo presente tal tonalidade busca preencher com "máscaras" e coisas supérfluas. E assim, o sofrimento que nos afeta, inutilmente quer ser preenchido, e os seres humanos querem fugir do drama existencial buscando significados vazios na objetividade da sociedade moderna e em um mundo dotado de saber científico e vazio cultural. Tentamos nos afastar de nós mesmos, de nossa própria vida, buscando algo que nem sabemos bem ao certo o que é e cada vez nos esvaziamos ainda mais. Passamos por um processo de ressignificação da vida, tornando-a objetiva e técnica, pois a fonte do conhecimento se tornou científica.

Nesse sentido, o foco do saber na técnica deixa de lado o saber da vida ressignificando o autodesenvolvimento por evidenciar um progresso técnico em contraponto com o regresso da cultura, provocando uma exclusão recíproca entre a ciência e a cultura. A técnica se distancia do autodesenvolvimento do ser e suas potencialidades fenomenológicas na vida e na cultura. Primeiramente, compreendido como uma descoberta marcante da humanidade, passa a produzir efeitos negativos na cultura do mundo da vida, enaltecendo a objetividade e excluindo a subjetividade como ponto de partida para o saber.

A ciência, pela técnica, ignora a vida, sua essência e sua sensibilidade. Ela faz abstração da sensibilidade por abstrair a própria vida. Assim, ao realizar um conhecimento objetivo da natureza, a ciência afasta o ver sensível e a vida de suas 
investigações, se tornando só e apenas uma técnica que designa os interesses superiores da humanidade em novas possibilidades para a utilização da ciência. Essa essência da técnica moderna é o autodesenvolvimento de processos que agem por si mesmos coordenados por um saber teórico da ciência, ou seja, são dispositivos instrumentais cada vez mais sofisticados que se produzem como autodesenvolvimento. Portanto, "a essência original da técnica não é um savoir-faire particular, é o savoir-faire como tal, ou seja, um saber que consiste no fazer, isto é, um fazer que traz em si seu próprio saber e o constitui" 16 , mas a técnica ameaça os fundamentos do ser através dos processos objetivos que são apenas dispositivos manipulados constantemente e não correspondem a vida originária.

O avanço científico estabelece a produção de uma abstração que não é a vida, mas o dinheiro gerado pelo capitalismo. Os fins subjetivos não são mais encontrados no próprio ser, mas fora dele, no mundo objetivo, no dinheiro e nos bens que o ser adquire enquanto ser capitalista. Portanto, "a ação e a regra não é mais o saber da vida, mas o da ciência: esta é a revolução radical que veio subverter a humanidade do homem, fazendo pairar sobre sua essência a mais grave ameaça a que ela esteve submetida desde o início dos tempos" ${ }^{17}$. Essa radicalidade corresponde a um grande abandono do saber afetivo do ser e de sua essência, tão grave quanto o abandono do verdadeiro viés cultural. A cultura é ressignificada com a exclusão do ser sensível do mundo da vida, em que "a ciência assim compreendida em sua plena concreção nada mais é que uma forma de cultura" 18 .

Os bens de consumo foram centralizados no mundo tomando tamanha importância, que ressignificou a dimensão ontológica do ser, descentralizando-o do mundo da vida. A técnica tomou o lugar da vida e a ciência se tornou um modo concreto da subjetividade, portanto, fundamentando também a cultura. Segundo Meira (2014, p.323), "a ciência cumpre na sociedade a função de promover uma fuga, uma negação da vida, o que denuncia a angústia comum a todos, o pathos". Nessa manifestação, o ser se nega a si mesmo adotando o tecnicismo como modo patético de autodesenvolvimento de si mesmo e se manifesta de forma patética na objetividade do mundo, procurando adquirir bens que supram essa necessidade subjetiva.

Enquanto modo concreto da ciência, a filosofia é rejeitada pela cultura, justificando o grande abandono do saber subjetivo pelo estudo da vida de onde parte todo o conhecimento. Nesse sentido, o retorno da cultura enquanto absoluta em sua manifestação originária não será mais possível. O próprio Henry nos descreve que é preciso ressignificá-la, pois "o grande mal-estar que percorre o mundo não será dissipado por um progresso do saber científico, mas pela vinda de novas formas de vida" (HENRY, 2011, p.213).

Para tanto, a cultura revela a vida imanente em seu movimento de autotransformação, partindo da necessidade e do trabalho como modalidades elementares da práxis. Sendo a subjetividade uma necessidade e o trabalho uma forma primordial de enraizamento da experiência humana, a cultura se potencializa e revela a essência da vida através da arte, da ética e da religião. A barbárie, como doença da vida, se apropria dessas formas superiores da cultura, objetivando-as e se distanciando da manifestação pura da vida. Nesse sentido, precisamos resgatar esses elementos essenciais para a superação da própria barbárie, visando um retorno a essência da vida ou subjetividade originária.

$\mathrm{Na}$ medida em que a vida se objetiva ela não é mais manifestada de forma absoluta, mas se converte em objeto de reflexão no mundo. Henry (2014) descreve que essa reflexão é motivada por um conjunto de subjetividades que tomam decisões para ações em comum no mundo designando um novo conhecimento absoluto e original, o 
qual ele chama de política ou democracia. Essa colabora para o trabalho enquanto primordial para a experiência humana e, portanto, se enraíza na cultura. O pathos, enquanto afetividade da vida, se manifesta pelas representações e ideias subjetivas constituindo ideologias.

210 Pela objetivação da vida no mundo, ela se distancia de sua sensibilidade gerando a manifestação patética de muitas angústias. A religião faz essa retomada do ser em si mesmo pela reaproximação com o sagrado enquanto experiência original do homem. Essa experiência arcaica do sagrado pode ser melhor compreendida através da estética. A cultura, por meio da arte, é expressada através da transcendência na imanência do si mesmo como manifestação do pathos, formando uma intersubjetividade patética e consequentemente uma sociedade religiosa (HENRY, 2014, p.416). Assim, a religião como forma de interpretação da sociedade e das subjetividades e, portanto, da Vida absoluta, vai sendo substituída pela democracia enquanto organização social de sujeitos livres.

Necessitamos de um processo de saber que influencie as dimensões estética, ética e religiosa do ser, afim de afetar sua essência enquanto princípio originário de realização da vida. A transmissão do saber humano é dada pelas universidades enquanto evidência constitutiva do saber (HENRY, 2012, p.188). A manifestação dessa evidência ocorre por determinações patéticas do ser em sua autoafecção que contribuem significativamente para a construção cognitiva, desde criança pela troca de afetos primeiramente com sua mãe e depois pelo saber transmitido em universidades. Essas determinações são produzidas no interior da subjetividade enquanto afetividade que se manifesta na vida. Henry enfatiza a sabedoria do homem de se aprimorar de todas as coisas que se modificam interiormente e exteriormente ao ser, mesmo o saber que ainda não lhes pertence. Portanto, nesta realidade modificada pela barbárie também vai se construindo a cultura enquanto uma nova forma de saber, já que a técnica invadiu o ensino das universidades e as próprias Ciências Humanas se tornaram objetivas.

O resgate da arte, da ética e da religião deve ocorrer a partir das universidades pelo saber humano como um retorno ao saber originário da vida. As leis e regras que regem a sociedade são instituídas a partir de universidades. A democracia como forma intersubjetiva de manifestação da liberdade e igualdade de direitos humanos diante da sociedade abre a possibilidade para revelar o poder da Vida porque as leis são leis da vida que designam a ética. Nesse sentido, é possível o retorno a forma originária da Vida por meio do resgate do saber sensível absoluto evidenciando as capacidades e os princípios que estão na essência do ser.

\section{CONSIDERaÇões FINAIS}

A partir de Michel Henry, podemos compreender melhor o contexto atual em que estamos vivendo. Diante do esquecimento da vida, em sua sensibilidade, somos levados ao mundo científico e passamos a agir de um modo objetivo. Isso significa que tratamos a vida, a natureza tecnicamente. E os resultados deste modo de pensar e agir nos leva conduz para o apega a materialidade, ao consumismo desenfreado e assim pensamos que estamos suprindo as nossas necessidades subjetivas. Isso nos leva a verdadeira barbárie, doença da vida, pela destruição da cultura e regressão do saber da vida, além da desordem social, cultural, política, moral e religiosa. O tecnicismo tomou conta e afetou também as universidades, a filosofia foi rejeitada enquanto abandono do saber da própria vida, a Estética tomou o lugar da cultura e as Ciências Humanas foram objetivadas. A ciência como nova forma de saber da técnica não consegue tratar as 
doenças da vida, pois essas caíram no esquecimento. É preciso ver que os sujeitos estão doentes pelo sofrimento ocasionado pelo distanciamento do Si subjetivo.

Para sairmos dessa barbárie, precisamos resgatar os princípios da sensibilidade absoluta e reconstruir a cultura do mundo da vida. As universidades como instituições de ensino devem retomar o verdadeiro significado do saber subjetivo ao trazer a arte, a ética e a religião como elementos que potencializam a cultura e revelam a essência da vida. Essas formas elementares precisam ser resgatadas a partir da barbárie, pois são elas que regem as manifestações subjetivas em suas diferentes formas de representação e que designam as leis da vida. A reflexão humana, portanto, se torna necessária neste momento acultural para que possamos ressignificar o Ser absoluto e sensível, o Ser da vida.

\section{REFERÊNCIAS}

FURTADO, Luiz José. A filosofia de Michel Henry: uma crítica fenomenológica da fenomenologia. Dissertatio, p. 231-249, inverno/verão de 2008. Disponível em: http://www.ufpel.edu.br/isp/dissertatio/revistas/27- 28/27-28-10.pdf.

HENRY, Michel. De la subjectivité. Tome II Phénoménologie de la vie. Paris: Épiméthée, PUF, 2003.

HENRY, Michel. L'essence de la manifestation. Paris: Épiméthée, PUF, 2011.

HENRY, Michel. O que é isso a que chamamos de vida?. In: MARQUES, R. V., MANZI FILHO, R. (Orgs). Paisagens da Fenomenologia Francesa. Trad. Rodrigo V. Marques. Conferência pronunciada na Universidade de Québec em Trois-Rivières, em primeiro de novembro de 1977. Curitiba: Editora UFPR, 2011.

HENRY, Michel. A Barbárie. Trad. Luiz Paulo Rouanet. São Paulo: É Realizações Editora, 2012.

HENRY, Michel. Difícil Democracia. Revista Ápeiron Estudios de Filosofia, Madrid, n. 1, p. 413432, 2014.

HENRY, Michel. O amor de olhos fechados. Trad. Pedro Sette-Câmara. São Paulo: É Realizações Editora, 2015.

KÜHN, Rolf. Ipseidade e Praxis Subjectiva: Abordagens fenomenológicas e antropológicas segundo o pensamento de Michel Henry. Trad. José Rosa, Helena de Jesus e Adelino Cardoso. Lisboa: Edições Colibri, 1944.

MARTINS, Florinda; SALDANHA, Marcelo. Michel Henry: critérios para avaliação de uma obra de arte. Revista da Fundarte, n.27, jan./jun. 2014, p. 55-64.

MEIRA, Valéria Peixoto. A barbárie na cultura da modernidade, sua banalização na sociedade e consequente perda dos significantes. Anais do Congresso Internacional da Faculdades EST, São Leopoldo, v.2, 2014, p. 318-326.

PALOMAR TORRALBO, Agustín. El valor cultural del arte en la época de la barbarie: la fenomenología estética de Michel Henry. Estudios de Filosofia, n.58, julh./dez. 2018, p. 143-167.

PRASERES, Janilce S. Fenomenologia da afetividade: um estudo a partir de Michel Henry. Dissertação (Mestrado em Filosofia) - Centro de Ciência Sociais e Humanas, Universidade Federal de Santa Maria. 2015.

\section{Notas}

1 Henry, em sua obra L'essence de la manifestation, descreve a vida como essência do ser em sua autoafecção enquanto uma fenomenologia radical. A vida se dá a si mesma em sua afetividade originária como imanência absoluta do ser.

2 HENRY, Michel. A Barbárie. Trad. Luiz Paulo Rouanet. São Paulo: É Realizações Editora, 2012 , p.26.

3 Pela afetividade, tudo o que se manifesta na vida e o que ela manifesta não se divergem no ato 
4 Ibid, p.45.

de autoafecção, assim como afirma Furtado (2008, p. 245): "Sua essência [da vida] é afetividade e afetividade quer dizer em Michel Henry auto-afecção em que afetante e o conteúdo afetado são a mesma coisa".

5 Para Henry, o pathos é a manifestação da afetividade originária no corpo patético, assim como afirma Praseres (2015, p. 45): “Todo ser é um si mesmo (passividade), somos passivos. Pathos, paixão, afecção, vida patética, é a própria afecção, o corpo é subjetivo. Para Henry nós não temos uma interioridade, somos a interioridade, pathos é definido como subjetividade originária transcendental, vai se revelando, auto se revela a mim. Visto que a afetividade é originária, já que o ser é originário, o pathos encontra-se como núcleo invisível da vida, é o que não se ver e não se pensa".

6 Ibid, p.53.

7 Ibid, p.49, grifos no original.

8 Ibid, p.31.

9 Ibid, p. 90.

$10 \mathrm{Ibid}$, p.27, grifos no original.

$11 \mathrm{Ibid}$, p. 103.

12 Ibid, p. 67.

13 Ibid, p.139.

14 Ibid, p. 190.

15 Ibid, p.85.

16 Ibid, p.78.

17 Ibid, p.85.

$18 \mathrm{Ibid}$, p.101. 